\title{
Performance analysis in emergency departments: a data-driven approach
}

\author{
Alessandro Stefanini * \\ Department of Department of Enterprise Engineering \\ University of Rome Tor Vergata \\ University Address: Via Orazio Raimondo, 00173, Rome, Italy \\ E-mail: alessandro.stefanini@uniroma2.it
}

\section{Davide Aloini}

Department of Energy, Systems, Territory and Construction Engineering University of Pisa

University Address: Largo Lucio Lazzarino 1, 56122, Pisa, Italy

E-mail: davide.aloini@dsea.unipi.it

\section{Elisabetta Benevento}

Inter-departmental Center for Logistic Systems (Livorno)

University of Pisa

University Address: Largo Lucio Lazzarino 1, 56122, Pisa, Italy

E-mail: benevento.elisabetta@libero.it

\section{Riccardo Dulmin}

Department of Energy, Systems, Territory and Construction Engineering University of Pisa

University Address: Largo Lucio Lazzarino 1, 56122, Pisa, Italy

E-mail: riccardo.dulmin@dsea.unipi.it

\section{Valeria Mininno}

Department of Energy, Systems, Territory and Construction Engineering University of Pisa

University Address: Largo Lucio Lazzarino 1, 56122, Pisa, Italy

E-mail: valeria.mininno@dsea.unipi.it

* Corresponding author 


\section{Structured Abstract}

Purpose - This paper aims to investigate the process performances in Emergency Departments with an innovative data-driven approach, permitting to discover the entire patient-flow, deploy the performances in term of time and resources on the activities and flows, and identify process deviations and critical bottlenecks. Moreover, the use of this methodology in real-time might dynamically provide a picture of the current situation inside the Emergency Department in term of waiting times, crowding, resources etc., enabling the management of patient demand and resources in real-time.

Design/methodology/approach - The proposed methodology exploits the processmining techniques. Starting from the event data inside the hospital information systems, it permits automatically to extract the patient-flows, to evaluate the process performances, to detect process exceptions, and to identify the deviations between the expected and the actual results.

Findings - The application of the proposed method to a real Emergency Department revealed being valuable in order to discover the actual patient-flow, measure the performances of each activity with respect to the predefined targets, and compare different operating situations.

Originality/value - This study responds to the need of novel approaches for monitoring and evaluating processes performances in the Emergency Departments. The novelty of this data-driven approach is the opportunity to timely connect performances, patient-flows and activities.

Practical implications - Starting from the results provided by this system, hospital managers could explore the root causes of deviations, devise improvement actions, and evaluate the effects of corrective actions.

Keywords - Process Performances, Emergency Department, Process Mining, Key Performance Indicators (KPIs), Healthcare Management, Hospital

Paper type - Research Paper 


\section{Introduction}

Emergency Departments (EDs) have gained a particular attention under the pressure of the public opinion and national authorities (Rebuge and Ferreira, 2012; Ganguly et al., 2014). The EDs' performance has the highest impact on patient care and is highly relevant in public opinion, e.g. public debate on excessive waiting time or misdiagnosis (Van der Vaart et al., 2011). Therefore, through the last years, following a major trend fostering continuous improvement in service organizations (Aloini et al., 2011), the need to improve the EDs' operational efficiency have attracted much attention of researchers and practitioners (Welch et al., 2011). National authorities for example have progressively posed more attention on ED performances and created some indicators in order to understand the service level offered to the patients. At first, the most of performances analyzed were connected to the emergency room waiting time and similar indicators. However, in order to avoid a distortionary effect (Kelman and Friedman, 2009), national authorities and researchers have also started to expand the performance dimensions under examination (Welch et al., 2011; Sørup et al., 2013).

In the aim to support an adequate assessment of EDs' KPI that could drive process improvement, two main challenges are still relevant for hospital managers. The first is the ability to provide and evaluate ED processes and related patient-flow by more detailed indexes rather than just synthetic indicators (Welch et al., 2011). A more in-depth knowledge of activity performances related with the patient-flow is really important because it might allow to identify the main process problems (e.g. bottlenecks, process anomalies, etc.) and thus to streamline/optimize the flows (Wiler et al., 2010). The second is the capacity to analyze ED processes rapidly, if possible in real-time, in order to enable a smarter management of the patient demand and ED resources (Hoot and Aronsky, 2008). The timely knowledge of operational performances and patient-related information, e.g. through an appropriate management dashboard, could permit to limit possible process risks and react effectively to undesirable situation in order to improve the patient care and resources control (Aronsky et al., 2008; Wiler et al., 2010).

While the expected benefits of such an analysis are potentially relevant, still some concerns exist, mainly due to the complexity of healthcare processes which are highly dynamic and interconnected, patient dependent and often multi-disciplinary in nature 
(Anyanwu et. al, 2003; Mans et al., 2009; Rebuge and Ferreira, 2012; Cannavacciuolo et al., 2017). Traditional approaches to business process analysis tend to be scarcely efficient, being very time-consuming, and low effective in such setting. In fact, they might not provide an accurate representation of the processes, and they cannot permit a timely analysis of patient-flows and process performances.

Trying to face the challenges above, this paper aims to investigate the process performances in Emergency Departments (EDs) exploiting an innovative data-driven approach based on process-mining techniques. It seems valuable because of the rising availability of information systems reporting process data. The proposed methodology, starting from the event log, permits to automatically extract the patient-flows, to evaluate process performances, and to identify the process and performance deviations between the expected and the real results. In addition, it allows to assess the performance of the whole ED system under different conditions and to compare the response to performance objectives, established by the hospital management. This method showing the link between performances, patient-flows, and process deviations could really support improvements for the ED processes. Furthermore, if applied to real-time data, it could provide a picture of the real situation inside the ED in term of waiting times, crowding, resources etc., enabling a smart management of patient demand and resources in the system.

\section{Background}

\subsection{ED Performance Measurement}

Although significant researches have been undertaken to investigate and monitor performance of EDs, the most of them were focused on key performance indicators that provide an overview of the entire ED system performances (i.e. waiting time, length of stay, etc.). These indicators, currently required by many national authorities, are typically estimated applying the traditional statistical approaches to the data stored in the ED information systems without the need for further elaborations (Graff et al., 2002; Welch et al., 2011; Shi et al., 2016).

However, this approach does not allow to figure out eventual local weaknesses and bottlenecks within the patient-flow and their impact on the patient's total time in ED (Sepehri et al., 2015; Khanna et al., 2017). In fact, the connections between the synthetic indicators and the critical activities in the patient-flows are really hard to assess. Thus, 
also corrective or improvement actions to be undertaken in order to increase quality of care and cut operational costs are difficult to identify (Wiler et al., 2010; Cannavacciuolo et al., 2015).

Since the rising amount of patient and process related data stored in the Electronic Health Record and other information systems, data-driven approaches as the Process Mining seems to be a viable solution for process identification and analysis in EDs.

Process mining aims to derive meaningful insights from the complex temporal relationships existing between activities and resources involved in processes (Partington et al., 2015). Indeed, by undertaking process mining, it is possible to gain insights into the hospital processes extracting the entire patient-flow, finding the performances of activities and flows in term of time and resources, and identifying process deviations and critical bottlenecks (Van der Aalst, 2011). Hence, this innovative approach results valuable for linking performances, patient-flows, and most critical activities.

\subsection{Process Mining}

Process mining is a relatively young research discipline that focuses on providing evidence-based process analysis techniques and tools for effective process management. The goal of process mining is to discover, monitor and analyze real processes by extracting knowledge from event logs recorded by information systems (Van der Aalst, 2011). The event data contained in the system log determines which process perspectives are possible to analyze. Currently, process mining considers four perspectives:

- Control-flow perspective. It focuses on extracting models describing process behavior, namely the activities in the process and their order of execution.

- Organizational perspective. It concentrates on the relationships between the agents who performed the activities.

- Data perspective. It centers on properties and data elements associated with individual process instances or tasks.

- Performance perspective. It focuses on the detection of bottlenecks and the estimation of performance indicators, such as throughput times and sojourn times (Van der Aalst, 2011; Rebuge and Ferreira, 2012).

Current research on process mining in the ED context is still underdeveloped but there are significant proofs of its applicability and potential usefulness (Partington et al., 2015; Rojas et al., 2016). 
Most of the studies focus on the control-flow perspective, deriving the process models and the execution properties from event logs recorded by ED Information Systems (Rebuge and Ferreira, 2012; Delias et al., 2015; Rovani et al., 2015; Rojas et al., 2016). On the other hand, the performance, organizational, and data perspectives of the process are less explored, especially for healthcare applications and particularly in EDs (Partington et al., 2015; Rojas et al., 2016).

As concerning the performance perspective, some authors have proved and discussed the suitability of process mining techniques to evaluate different classes of performance indicators (e.g., average/variance of the total flow time or the time spent between two activities, etc.) and bottlenecks within the process, typically by case studies approach (Rebuge and Ferreira, 2012; Rovani et al, 2015). Others have directed the attention on comparing the ED workflows and their performance between different hospitals, in order to gain insights into how process behaviors differ and elicit knowledge about improvement opportunities (Delias et al., 2015; Partington et al., 2015; Suriadi et al., 2014). At the best of our knowledge, nobody has developed or formalized a performance measurement system for monitoring and evaluating the process performance in $\mathrm{ED}$, based on process mining.

\section{Research objective}

This paper aims to suggest a methodology for monitoring and evaluating the process performances in Emergency Departments (EDs), exploiting an innovative quantitative approach based on process mining techniques. This approach exploits process mining to overcome some limitations of the traditional techniques when applied to highly dynamic processes, like the emergency care (Rebuge and Ferreira, 2012; Partington et al., 2015). Starting from the event data integrated with other information available, this method is able to dynamically extract the process model, to evaluate indicators and process performances, to detect process deviances, and to identify the deviations between the expected and the actual results.

More in detail, the following objectives can be determined:

- Identify the real patient-flows and map the related activities inside the Emergency Department

- Evaluate the ED Key Performance Indicators including those required by national and regional authorities and the related deviations. 
- Estimate the waiting and execution times of activities and diagnose the process bottlenecks (possibly considering the available resources).

- Compare the real patient-flows with expected patient-flows or external guidelines, in order to detect process anomalies and/or procedure anomalies.

- Eventually assess and compare the performance of whole ED system under different conditions (e.g., normal operating conditions, overcrowding, different resource availability, different operating procedure/layout, etc.), in order to measure vulnerabilities against a set of events or scenario and to evaluate the effect of system changes.

- Explore the root causes of deviations and devise improvement/corrective actions.

\section{$4 \quad$ Proposed methodology}

The proposed methodology goes through the following five main phases:

- Identification of performance indicators to evaluate and monitor the ED processes. The dashboard of KPIs was built up keeping in consideration both the synthetic measures required by national and regional authorities and devising additional indicators through an accurate analysis of the literature in line with hospital goals defined in collaboration with hospital managers.

- Data collection and preparation, which involves extraction and pre-processing of event data, gathered from the hospital information systems. The collected event data concern the registrations of activities performed for the ED patients during a specified period of time. The event log is refined by removing irrelevant data, incomplete information, and errors in order to enable the next analysis stage.

- Process discovery phase aims to discover the overall process model for the emergency department. Many process mining techniques can be used in this phase with the support of process mining tools, like Disco and ProM (Van der Aalst, 2011).

- Process monitoring phase aims to compute the KPIs identified at the step 1 by applying statistical techniques and using process mining tools as Disco and ProM. KPI deviations can be evaluated as stand-alone or in respect to predefined targets. Exploiting the process map mined in the previous phase it is also possible to drill down the process measures and consider the performance of 
each relevant activity accordingly to different evaluation perspectives: time, cost, and resource. For example, if event data reports the information about the resources involved in the activities, resource productivity could be easily estimated.

- Process analysis. KPI and deviations are deeply analyzed to identify where and why deviances occur in the process. In this phase, in collaboration with hospital managers and experts, it is possible to try to investigate the main path deviances and bottlenecks on the patient-flows with the support of process mining, in particular the conformance checking techniques. Specifically, conformance checking permits to identify and quantify the deviations between the actual and the expected patient-flows (Mans et al., 2009; Van der Aalst, 2011). In this way, it is possible to find the most critical process deviances in term of activities and administrative/informative procedures.

- Performance comparison. If relevant, the method assess and compare the performance of the ED system in different situations. By repeating the proposed methodology with different data sets, it is possible to estimate the performances of the ED system under different operating conditions (e.g. different operating procedures/layout, different resource availability, stress situations like overcrowding, after the implementation of improvements, etc.) and compare them to the performances achieved under normal conditions. Thus, the differences between process performances are analyzed, measuring the percentage variation in process measures across different periods and the gap from the pre-defined targets. In this way, by exploring and comparing the associated ED pathways, it is possible to check where process behaviors differ drastically between different periods (e.g., under-performing or overachieving) and identify the roots of the variations.

Summarizing, the proposed methodology would like to help the hospital management to understand the ED processes and related performances, investigate the root causes of deviations, and provide relevant indications for process improvement in the emergency department. 


\section{Case study}

The proposed methodology was tested with a case study inside a real Emergency Department. We used a dataset, provided by the hospital, that records patient's journey inside the ED in the 2016.

\subsection{Identification of performance indicators}

Following the methodology, we started analyzing the current scientific literature (e.g. Khalifa et al., 2015; Sørup et al., 2013; Welch et al., 2011) and selecting the most appropriate indicators to measure ED performances. The first set of KPIs was extended with the indexes set out by the regional authority and the indicators suggested by the hospital management, according to their hospital goals.

The resultant 20 indicators were sorted in two categories, as shown in fig 1.

Insert figure 1 here

Each category reflects specific performance objectives (Khalifa et al., 2015). In particular, patient-related indicators can measure the patient satisfaction level and the degree to which ED succeed or fail in meeting patient needs. Process indicators, instead, deal primarily with patient throughput/patient-flows and with the overall ED efficiency which is related to resource use. Moreover, time measures include both global synthetic indicators for assessing the performances of the entire ED and measures evaluating performance of each activity within the ED processes. Keeping the duration of activities short means reducing crowding and keeping an efficient patient-flow. We measured all indicators both in absolute terms and in respect to the target values required by national and regional authorities.

\subsection{Data collection and preparation}

In the second step, we collected and pre-processed data of all patients who presented to the ED from February 2016 to April 2016. Data was mostly gathered from the Emergency Department Information Systems. We decided to remove from the event log incomplete data and to aggregate overly low-level activities. This resulted in a $\log$ of more than 9,670 patient cases that consisted of more than 72,770 events. Note that for each event the timestamp (i.e. when the event took place) was recorded. Finally, we 
decided to group patient cases accordingly to their triage category, in line with the criteria defined by the regional authority. Each groups can have different patient-flows within the ED and, hence, different performances.

We identify five patient groups, according to their requirements:

- Red code: immediate patient, i.e., patient in need of immediate treatment for preservation of life.

- Yellow code: very-urgent patient, i.e., seriously ill or injured patients whose lives are not in immediate danger.

- Green code: urgent patients with serious problems, but apparently stable condition.

- Blue code: standard patients without danger or distress.

- White code: non-urgent patients, whose conditions are not true accidents or emergencies.

\subsection{Process discovery}

Process discovery was conducted applying the Fuzzy Miner as implemented by Disco and the Inductive Miner as implemented by ProM. The discovered process models reflect the actual processes as observed through real process executions inside the ED. Fig. 2, as example, shows the patient-flows produced by Disco tool for urgent patients, the highest percentage of patients in the ED.

The discovered process map allowed to obtain in-depth information and knowledge about the structure of the process, the main patient-flows and the frequency of activities and paths among them.

Insert figure 2 here

\subsection{Process monitoring}

After that, we measured the KPIs identified in the first step of the methodology. The measurement was performed by Disco and ProM tools. In particular, time information (e.g., total or mean throughput time or waiting time for each transition, etc.) are graphically shown on the process model and, hence, used to highlight bottlenecks within the process. In this way, we were able to gain deep insights regarding the time 
performance of each activity and related resource consumptions. For example, we can measure the time interval from a request for laboratory exam and the availability of its results or the waiting time for a patient to receive a radiological report.

Table 1 summarizes the results obtained. In particular, it shows performance related information of the ED processes during the months February, March and April 2016.

\section{Insert table 1 here}

All KPIs can be measured for each group of patients with the same triage category. The insights from this analysis enabled to identify bottlenecks for each group. For example, when analyzing the performance of urgent patients, it was found a bottleneck in the waiting time between the arrival of the $\mathrm{x}$-ray results and the start of the orthopedic visit. It was, on average, 46.4 minutes and turns out to be too high.

Table 2 summarizes the results of the performance analysis for urgent patients.

Insert table 2 here

Finally, we compared the KPI values obtained from the ED performance analysis with the target values required by the national/regional authorities and by the management of the hospital. The results are presented in table 3 .

\section{Insert table 3 here}

\subsection{Process analysis}

The last step concerns the analysis of the process and KPIs deviations.

First, with the support of the ED staff and hospital management, we analyzed the KPI deviations from the target values. Starting from the results shown in table 3, we can point out some interesting insights about these deviations. For example, the KPIs related to the red, yellow and green codes had much lower value than the target value. In light of this, the hospital management should prioritize patient-flow interventions aimed at improving 
operations after triage and then at reducing the waiting time before the physician visit for immediate, urgent and very urgent patients. Moreover, the laboratory staff should review its reporting practices in order to shorten the reporting time. Improving the laboratory performance, in fact, could reduce the length of stay of patients in the emergency department.

Second, exploring the discovered process model may give some interesting insights about process deviations and where they can potentially originate. For example, for the $17 \%$ of patient cases, various activities were recorded after the discharge from the ED. In particular, very often (the $15 \%$ of cases) radiological or medical reports were delivered after the discharge. Instead, rarely ( $2 \%$ of cases) medications or blood sampling appear as end activities. According to the hospital management, the reason of this discrepancy may be due to a delay in data entry by physicians or nurses or to an incorrect data entry.

The above mentioned results enabled ED staff not only to identify process/KPI deviations but also to identify the root causes of these deviations. For example, for discharged urgent patients, the long waiting time between radiological activity and orthopedic visit can be recognize as possible cause for the high value of throughput time observed. In fact, urgent patients which get a length of stay longer than 4 hours, also wait an average of 103.7 minutes before the start of the consultation.

Moreover, results showed that patients might decide to leave the ED without being seen by a physician or before treatment complete after waiting more than 2 hours between following activities.

\subsection{Performance comparison}

Finally, in agreement with the hospital management, we decided to compare performance level achieved by the ED in winter (normal situation) with level achieved in summer (overcrowding situation).

Indeed, the patients admitted to ED was estimated to be $30 \%$ higher during summer than the rest of the 2016, due to the hospital location in a sea area. In particular, in July and August the ED accesses were on average 4350 per month (compared to 3200 per month in winter). However, the resources remained constant during the year (i.e., 7 nurses and 5 doctors on day shifts, 5 nurses and 2 doctors on night shift).

In this way, we were able to assess to which extent the performance of whole ED system is stable under overcrowding conditions and identify the potential vulnerabilities. 
Firstly, we collected and pre-processed data of all patients who presented to the ED between July 1 and August 31,2016. Then, we measured ED performances and analyzed process deviations according to the methodology.

Comparing the results of performance analyses conducted in winter and summer, a number of interesting differences were observed in practice. The main comparative findings are presented here.

Firstly, we measured the discrepancies in the time performances across the two periods (Table 4).

Insert table 4 here

As shown in table 4, we observed an overall worsening of the time performances inside the ED under overcrowding conditions. Evidence shows that there was an increase in LOS for discharged and admitted patients (about 4\% and 6\% respectively) due to increased waiting times between activities.

When looking at the performance of each activity, we were able to check which activities had a negative impact on the performance of the overall ED process.

For example, we noticed a significant variation in time to treatment (approximatively $20 \%$ ) and in the wait attributed to lab test results (approximatively $7.5 \%$ ) during summer. However, patients admitted to ED between July and August had the shortest waits to leave the department (on average $38 \mathrm{~min}$ ), despite the crowding inside the structure.

Note that, a significant worsening of the performance of such activities led to a decreased of the quality perceived by the patient, as demonstrated by the values of the patient-related measures (Table 5).

Insert table 5 here

As shown in table 5, the proportion of patients who left the ED without being seen or before being discharged by a physician has increased on average by $0.5 \%$ in summer. 
In addition, a detailed performance comparison is provided between the two periods against hospital target values and national/regional target guidelines (Table 6).

\section{Insert table 6 here}

As shown in table 6, the gaps between the KPI values measured in summer and the target values have increased.

For example, the proportion of urgent patients, with time to treatment less than one hour, dropped to $69 \%$ from $75 \%$, which was $21 \%$ below the regional target. Moreover, in summer the number of lab results delivered in less than one hour was almost halved compared to the hospital's requirement, due to the greater number of accesses to the ED.

Finally, comparing the ED associated pathways (discovered previously), we can identify the roots of these dissimilarities. Note that, the variation in the stages where the greatest proportion of waiting occurred may be the cause of an increase in cases that did not meet the regional/national and hospital standards.

For example, as shown in fig 3, although the waiting time between radiological activity and orthopedic visit remained constant, in summer urgent patients, with a LOS longer than 4 hours, waited on average 93 minutes before the first visit (compared to 80 $\min$ in winter). Besides, the laboratory reporting time increased by at least 7 minutes.

Insert figure 3 here

Moreover, we observed that the $4.6 \%$ of patients decide to leave the ED in summer due to the increase in waiting time before patient being seen by a physician (approximately 13\%) or before treatment complete (approximately 14\%).

\section{Discussion \& Conclusions}

In this study, we propose a novel approach to monitor and evaluate performances of an Emergency Department. Process mining reveals being valuable in the presence of highly complex processes as such as an ED in the aim to discover the actual patient-flow and provide hospital managers with deep insights regarding the performances of each 
activity in terms of waiting time and consumed resources. In so doing, the main contributions of this paper are as follows:

- It enables the continuous monitoring of the ED process performances, possibly in real-time;

- It supports the identification of potential process deviations and enables to identify bottlenecks in the patient-flow quantifying their impact on the performances of the entire ED;

- It assists in detecting the causes of deviations, identifying areas for improvements within the ED processes and finding/testing possible solutions. In fact, the process mining outputs can provide managers useful information for the simulation studies in order to evaluate performances of alternative operational scenarios.

In addition, this approach allows to assess to which extent the performance of whole ED system is stable under overcrowding conditions and identify the potential vulnerabilities. The results provide detailed insights into the key differences in ED performance across different periods and highlight the underlying causes for the variations in patient-flows and their performance, in order to understand their impacts on clinical outcomes.

Moreover, the approach can be also expanded to wider care organizations, at regional or national level, with the aim of a cross-organizational benchmarking of ED processes and their performance. Indeed, it could enable the identification of similarities and differences in clinical practices across different hospitals, with a focus on process behaviors and the respective performances. This could be helpful for organizations and authorities, since it might allow to identify best practices, and monitor investment decisions and decisions on changes in practice.

Future developments include the development of an ED dashboard of KPIs that might allow to monitor and assess process performances. It could enable real time decision making when unplanned critical situations occur in particular points of the ED processes. The appropriate knowledge of activity performances might help hospital managers to properly manage the utilization of resources during the shift/day in order to increase the level of service and reduce the waiting time within the ED. 


\section{References}

Aloini, D., Martini, A., and Pellegrini, L. (2011), "A structural equation model for continuous improvement: a test for capabilities, tools and performance", Production Planning \& Control, 22(7), pp. 628-648.

Anyanwu, K., Sheth, A.P., Cardoso, J., Miller, J.A. and Kochut, K.J. (2003), "Healthcare enterprise process development and integration".

Aronsky, D., Jones, I., Lanaghan, K. and Slovis, C. M. (2008), "Supporting patient care in the emergency department with a computerized whiteboard system", Journal of the American Medical Informatics Association, 15(2), pp. 184-194.

Cannavacciuolo, L., Illario, M., Ippolito, A. and Ponsiglione, C. (2015), “An activity-based costing approach for detecting inefficiencies of healthcare processes", Business Process Management Journal, 21(1), pp. 55-79.

Cannavacciuolo, L., Iandoli, L., Ponsiglione, C., Maracine, V., Scarlat, E. and Nica, A. S. (2017), "Mapping knowledge networks for organizational re-design in a rehabilitation clinic", Business Process Management Journal, 23(2).

Delias, P., Doumpos, M., Grigoroudis, E., Manolitzas, P. and Matsatsinis, N. (2015), "Supporting healthcare management decisions via robust clustering of event logs", Knowledge-Based Systems, 84, pp. 203-213.

Ganguly, S., Lawrence, S. and Prather, M. (2014), "Emergency department staff planning to improve patient care and reduce costs", Decision Sciences, 45(1), pp. 115-145.

Graff, L., Stevens, C., Spaite, D. and Foody, J. (2002), "Measuring and improving quality in emergency medicine", Academic Emergency Medicine, 9(11), pp. 1091-1107.

Hoot, N. R. and Aronsky, D. (2008), "Systematic review of emergency department crowding: causes, effects and solutions", Annals of emergency medicine, 52(2), pp. 126-136.

Huang, J., Carmeli, B. and Mandelbaum, A. (2015), "Control of patient flow in emergency departments, or multiclass queues with deadlines and feedback", Operations Research, 63(4), pp. 892-908.

Khalifa, M. and Khalid, P. (2015), "Developing Strategic Health Care Key Performance Indicators: A Case Study on a Tertiary Care Hospital”, Procedia Computer Science, 63, pp. 459-466.

Khanna, S., Boyle, J., Good, N., Bell, A. and Lind, J. (2017), “Analysing the emergency department patient journey: Discovery of bottlenecks to emergency department patient flow", Emergency Medicine Australasia, 29(1), pp. 18-23.

Kelman, S. and Friedman, J. N. (2009), "Performance improvement and performance dysfunction: an empirical examination of distortionary impacts of the emergency room wait-time target in the English National Health Service", Journal of Public Administration Research and Theory.

Mans, R. S., Schonenberg, M. H., Song, M., van der Aalst, W. M. and Bakker, P. J. (2009), "Application of process mining in healthcare-a case study in a Dutch hospital", Springer Berlin Heidelberg, pp. 425-438.

Partington, A., Wynn, M., Suriadi, S., Ouyang, C. and Karnon, J. (2015), "Process mining for clinical processes: a comparative analysis of four Australian hospitals", ACM Transactions on Management Information Systems (TMIS), 5(4), p. 19.

Rebuge, Á. and Ferreira, D.R. (2012), "Business process analysis in healthcare environments: A methodology based on process mining”, Information Systems, 37(2), pp. 99-116.

Rojas, E., Munoz-Gama, J., Sepúlveda, M. and Capurro, D. (2016), "Process mining in healthcare: A literature review", Journal of biomedical informatics, 61, pp. 224-236.

Rovani, M., Maggi, F. M., de Leoni, M. and van der Aalst, W. M. (2015), "Declarative process mining in healthcare", Expert Systems with Applications, 42(23), 9236-9251. 
Sepehri, Z., Arabzad, S. M. and Sajadi, S. M. (2015), "Analysing the performance of emergency department by simulation: the case of Sirjan Hospital", International Journal of Services and Operations Management, 20(3), pp. 289-301.

Shi, P., Chou, M. C., Dai, J. G., Ding, D. and Sim, J. (2016), "Models and insights for hospital inpatient operations: Time-dependent ED boarding time", Management Science, 62(1), pp.128 .

Sørup, C. M., Jacobsen, P. and Forberg, J. L. (2013), "Evaluation of emergency department performance-a systematic review on recommended performance and quality-in-care measures", Scandinavian journal of trauma, resuscitation and emergency medicine, 21(1), pp. 62.

Suriadi, S., Mans, R. S., Wynn, M. T., Partington, A. and Karnon, J. (2014), "Measuring patient flow variations: A cross-organisational process mining approach", In Asia-Pacific Conference on Business Process Management, Springer, Cham, pp. 43-58

Van der Aalst, W. (2011), "Process mining: discovery, conformance and enhancement of business processes", Springer Science and Business Media.

Van der Vaart, T., Vastag, G. and Wijngaard, J. (2011), "Facets of operational performance in an emergency room (ER)", International Journal of Production Economics, 133(1), pp. 201-211.

Welch, S. J., Asplin, B. R., Stone-Griffith, S., Davidson, S. J., Augustine, J., Schuur, J. and Alliance, E. D. B. (2011), "Emergency department operational metrics, measures and definitions: results of the second performance measures and benchmarking summit", Annals of emergency medicine, 58(1), pp. 33-40.

Wiler, J. L., Gentle, C., Halfpenny, J. M., Heins, A., Mehrotra, A., Mikhail, M. G. and Fite, D. (2010), "Optimizing emergency department front-end operations", Annals of emergency medicine, 55(2), pp. 142-160. 


\begin{tabular}{|c|c|c|c|c|c|}
\hline $\begin{array}{l}\text { Patient-related } \\
\text { indicators }\end{array}$ & $\begin{array}{l}\text { Value } \\
(\%)\end{array}$ & Time measure & $\begin{array}{l}\text { Value } \\
\text { (minute } \\
\text { s) }\end{array}$ & $\begin{array}{l}\text { Resource } \\
\text { utilization }\end{array}$ & $\begin{array}{l}\text { Value } \\
\text { per } \\
\text { person }\end{array}$ \\
\hline $\begin{array}{l}\text { Unplanned re- } \\
\text { attendance } \\
(<72 \mathrm{~h})\end{array}$ & $5.6 \%$ & $\begin{array}{l}\text { Length of Stay } \\
\text { for discharged } \\
\text { patients }\end{array}$ & 150 & $\begin{array}{l}\text { Number of } \\
\text { specialty } \\
\text { consultation }\end{array}$ & 0.58 \\
\hline $\begin{array}{l}\text { Left without } \\
\text { being seen }\end{array}$ & $2.6 \%$ & $\begin{array}{l}\text { Length of Stay } \\
\text { for admitted } \\
\text { patients }\end{array}$ & 198 & $\begin{array}{l}\text { Number of CT } \\
\text { studies }\end{array}$ & 0.14 \\
\hline $\begin{array}{l}\text { Left before } \\
\text { treatment } \\
\text { complete }\end{array}$ & $1 \%$ & $\begin{array}{l}\text { Time to } \\
\text { treatment }\end{array}$ & 35 & $\begin{array}{l}\text { Number of MRI } \\
\text { studies }\end{array}$ & 0.01 \\
\hline $\begin{array}{l}\text { Left against } \\
\text { medical advice }\end{array}$ & $1.8 \%$ & $\begin{array}{l}\text { Doctor to } \\
\text { discharge time }\end{array}$ & 36 & $\begin{array}{l}\text { Number of plain } \\
\text { radiography } \\
\text { studies }\end{array}$ & 0.46 \\
\hline Admission rate & $8 \%$ & $\begin{array}{l}\text { Doctor to } \\
\text { decision to } \\
\text { admit time }\end{array}$ & 57.3 & Number of ECG & 0.30 \\
\hline \multirow[t]{2}{*}{$\begin{array}{l}\text { SSOU Transfer } \\
\text { rate }\end{array}$} & $9 \%$ & $\begin{array}{l}\text { Radiology } \\
\text { interval }\end{array}$ & 36.2 & $\begin{array}{l}\text { Number of } \\
\text { ultrasonic } \\
\text { studies }\end{array}$ & 0.16 \\
\hline & & $\begin{array}{l}\text { Laboratory } \\
\text { interval }\end{array}$ & 53.1 & $\begin{array}{l}\text { Number of } \\
\text { laboratory } \\
\text { studies }\end{array}$ & 0.53 \\
\hline
\end{tabular}




\begin{tabular}{|c|c|c|c|c|c|}
\hline $\begin{array}{l}\text { Patient- } \\
\text { related } \\
\text { indicators }\end{array}$ & $\begin{array}{l}\text { Value } \\
(\%)\end{array}$ & $\begin{array}{l}\text { Time } \\
\text { measure }\end{array}$ & $\begin{array}{l}\text { Value } \\
\text { (minutes) }\end{array}$ & $\begin{array}{l}\text { Resource } \\
\text { utilization }\end{array}$ & $\begin{array}{l}\text { Value per } \\
\text { person }\end{array}$ \\
\hline $\begin{array}{l}\text { Left without } \\
\text { being seen }\end{array}$ & $2 \%$ & $\begin{array}{l}\text { Length of Stay } \\
\text { for discharged } \\
\text { patients }\end{array}$ & 150 & $\begin{array}{l}\text { Number of } \\
\text { specialty } \\
\text { consultation }\end{array}$ & 0.55 \\
\hline $\begin{array}{l}\text { Left before } \\
\text { treatment } \\
\text { complete }\end{array}$ & $1 \%$ & $\begin{array}{l}\text { Length of Stay } \\
\text { for admitted } \\
\text { patients }\end{array}$ & 252 & $\begin{array}{l}\text { Number of CT } \\
\text { studies }\end{array}$ & 0.09 \\
\hline $\begin{array}{l}\text { Left against } \\
\text { medical } \\
\text { advice }\end{array}$ & $1.8 \%$ & $\begin{array}{l}\text { Time to } \\
\text { treatment }\end{array}$ & 38.4 & $\begin{array}{l}\text { Number of } \\
\text { MRI studies }\end{array}$ & 0.01 \\
\hline $\begin{array}{l}\text { Admission } \\
\text { rate }\end{array}$ & $3 \%$ & $\begin{array}{l}\text { Doctor to } \\
\text { discharge time }\end{array}$ & 22.4 & $\begin{array}{l}\text { Number of } \\
\text { plain } \\
\text { radiography } \\
\text { studies }\end{array}$ & 0.41 \\
\hline \multirow[t]{3}{*}{$\begin{array}{l}\text { SSOU } \\
\text { Transfer rate }\end{array}$} & \multirow[t]{3}{*}{$4 \%$} & $\begin{array}{l}\text { Doctor to } \\
\text { decision to } \\
\text { admit time }\end{array}$ & 80.4 & $\begin{array}{l}\text { Number of } \\
\text { ECG }\end{array}$ & 0.18 \\
\hline & & $\begin{array}{l}\text { Radiology } \\
\text { interval }\end{array}$ & 37.7 & $\begin{array}{l}\text { Number of } \\
\text { ultrasonic } \\
\text { studies }\end{array}$ & 0.17 \\
\hline & & $\begin{array}{l}\text { Laboratory } \\
\text { interval }\end{array}$ & 55.4 & $\begin{array}{l}\text { Number of } \\
\text { laboratory } \\
\text { studies }\end{array}$ & 0.40 \\
\hline
\end{tabular}

Table 2: KPIs for urgent patients

KPIs

Target value Obtained value

(\%)

$(\%)$

\begin{tabular}{|lcc|}
\hline $\begin{array}{l}\% \text { Of discharged urgent patients with length of Stay }< \\
4 \mathrm{~h}\end{array}$ & $>90 \%$ & \\
\hline$\%$ Of admitted patients with length of Stay $<8 \mathrm{~h}$ & $>95 \%$ & $98 \%$ \\
\hline$\%$ Of non-urgent patients with time to treatment $<4 \mathrm{~h}$ & $>75 \%$ & $91 \%$ \\
\hline$\%$ Of standard patients with time to treatment $<2 \mathrm{~h}$ & $>75 \%$ & $86 \%$ \\
\hline$\%$ Of urgent patients with time to treatment $<1 \mathrm{~h}$ & $>90 \%$ & $75 \%$ \\
\hline $\begin{array}{l}\% \text { Of very urgent patients with time to treatment }<30 \\
\text { min }\end{array}$ & $>90 \%$ & $78 \%$ \\
\hline
\end{tabular}




\begin{tabular}{|lcc|}
\hline $\begin{array}{l}\% \text { Of immediate patients with time to treatment }<5 \\
\text { min }\end{array}$ & $>99 \%$ \\
\hline$\%$ Of lab results delivered within $1 \mathrm{~h}$ & $>95 \%$ & $64 \%$ \\
\hline $\begin{array}{l}\% \text { Of patients who left without being seen or before } \\
\text { treatment complete }\end{array}$ & $<2.3 \%$ & $3.6 \%$ \\
\hline$\%$ Of unplanned re-attendance $(<72 \mathrm{~h})$ & $<5.4 \%$ & $5.6 \%$ \\
\hline
\end{tabular}

Table 3: Comparison between the KPI values obtained from the performance analysis and the target values required by the authorities and the hospital management

Time measure

\begin{tabular}{|c|c|c|c|}
\hline & April 2016 & 2016 & change \\
\hline Length of stay for discharged patients & $150 \mathrm{~min}$ & $156 \mathrm{~min}$ & $+4 \%$ \\
\hline Length of stay for admitted patients & $198 \mathrm{~min}$ & $210 \mathrm{~min}$ & $+6 \%$ \\
\hline Time to treatment & $35 \mathrm{~min}$ & $42.8 \mathrm{~min}$ & $+22 \%$ \\
\hline Radiology interval & $36.2 \mathrm{~min}$ & $37.8 \mathrm{~min}$ & $+4.4 \%$ \\
\hline Laboratory interval & $53.1 \mathrm{~min}$ & $57.1 \mathrm{~min}$ & $+7.5 \%$ \\
\hline Doctor to discharge time & $36 \mathrm{~min}$ & $33 \mathrm{~min}$ & $-8 \%$ \\
\hline Doctor to decision to admit time & $57.3 \mathrm{~min}$ & $43 \mathrm{~min}$ & $-24 \%$ \\
\hline
\end{tabular}

Table 4: Comparison between time performances across winter and summer

\begin{tabular}{|l|c|c|c|}
\hline \multicolumn{1}{|c}{ Patient-related indicators } & $\begin{array}{c}\text { February-April } \\
\mathbf{2 0 1 6}\end{array}$ & $\begin{array}{c}\text { July-August } \\
\mathbf{2 0 1 6}\end{array}$ & $\begin{array}{c}\text { Percentage } \\
\text { change }\end{array}$ \\
\hline Left without being seen & $2.6 \%$ & $3.2 \%$ & $+0.6 \%$ \\
\hline Left before treatment complete & $1 \%$ & $1.4 \%$ & $+0.4 \%$ \\
\hline Left against medical advice & $1.8 \%$ & $2 \%$ & $+0.2 \%$ \\
\hline
\end{tabular}

Table 5: Comparison between patient-related measures across winter and summer 


\begin{tabular}{|l|c|c|c|c|}
\cline { 2 - 4 } \multicolumn{1}{l|}{} & $\begin{array}{c}\text { Obtained } \\
\text { value }\end{array}$ & $\begin{array}{c}\text { Gap from } \\
\text { the target } \\
\text { value }\end{array}$ & $\begin{array}{c}\text { Obtained } \\
\text { value }\end{array}$ & $\begin{array}{c}\text { Gap from } \\
\text { the target } \\
\text { value }\end{array}$ \\
\hline $\begin{array}{l}\% \text { Of discharged urgent patients with } \\
\text { length of Stay }<4 \mathrm{~h}\end{array}$ & $84 \%$ & $6 \%$ & $78 \%$ & $12 \%$ \\
\hline $\begin{array}{l}\text { \% Of admitted patients with length of } \\
\text { Stay }<8 \mathrm{~h}\end{array}$ & $98 \%$ & - & $96 \%$ & - \\
\hline $\begin{array}{l}\% \text { Of non-urgent patients with time to } \\
\text { treatment }<4 \mathrm{~h}\end{array}$ & $91 \%$ & - & $90 \%$ & - \\
\hline $\begin{array}{l}\% \text { Of standard patients with time to } \\
\text { treatment }<2 \mathrm{~h}\end{array}$ & $86 \%$ & - & $81 \%$ & - \\
\hline $\begin{array}{l}\% \text { Of urgent patients with time to } \\
\text { treatment }<1 \mathrm{~h}\end{array}$ & $75 \%$ & $15 \%$ & $69 \%$ & $21 \%$ \\
\hline $\begin{array}{l}\% \text { Of very urgent patients with time to } \\
\text { treatment }<30 \text { min }\end{array}$ & $78 \%$ & $12 \%$ & $71 \%$ & $19 \%$ \\
\hline $\begin{array}{l}\% \text { Of immediate patients with time to } \\
\text { treatment }<5 \text { min }\end{array}$ & $60 \%$ & $39 \%$ & $68 \%$ & $31 \%$ \\
\hline $\begin{array}{l}\% \text { Of lab results delivered within } 1 \mathrm{~h} \\
\text { seen or before treatment complete }\end{array}$ & $64 \%$ & $31 \%$ & $49 \%$ & \\
\hline
\end{tabular}

Table 6: Performance comparison between winter and summer against national/regional and hospital target value 



\section{Figure 2: The discovered process model for urgent patients}
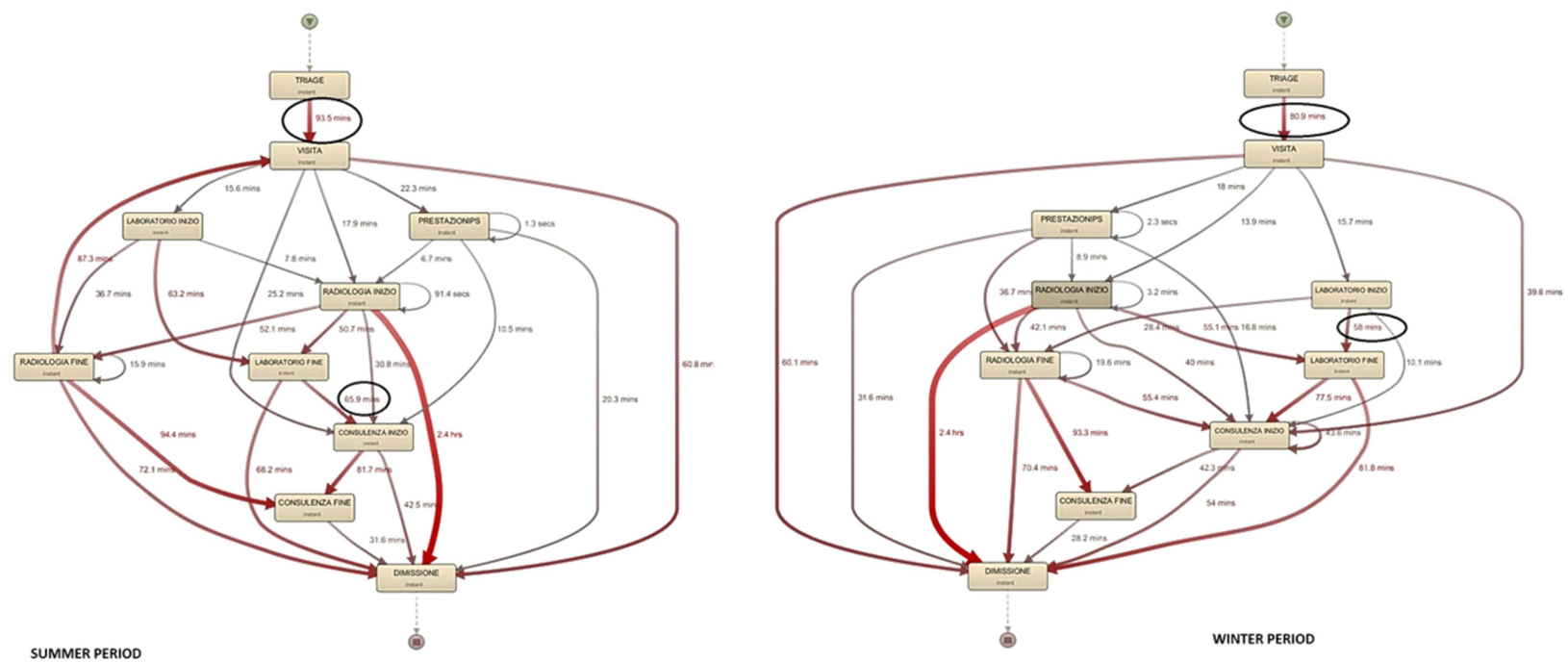

Figure 3: Care pathways of urgent patients with a LOS longer than 4 hours in summer and winter 